\title{
Gerontological Nursing Students' Evaluation and Feedback about Objective Structured Clinical Examination
}

\author{
Soad Hassan Abd Elhameed, Assistant Professor \\ Gerontological Nursing, Faculty of Nursing, Mansoura University \\ Doaa Abd Elhameed Abd Elmawla, Lecturer \\ Gerontological Nursing, Faculty of Nursing, Mansoura University
}

\begin{abstract}
Objective structured clinical examination (OSCE) is one form of objective evaluation method that is gaining more acceptance and is being adopted by educators of various disciplines. Now, OSCE becomes a popular tool for assessing competency in clinical nursing and is applied in other branches of health sciences as dentistry and pharmacy. In OSCE evaluation of the clinical skills is crucial feedback and it plays a very important motivating role between students and academics to confirm the standard and appropriateness of a learning process. Objective: Determine the gerontological nursing students' evaluation and feedback about objective structured clinical examination. Setting: The study was carried out at Faculty of Nursing, Mansoura University, Egypt. Subjects: The study included 289 of undergraduate $4^{\text {th }}$ level students enrolled in gerontological nursing course in the first and second semester during the academic year 2016/2017. Tools: Data was collected using three tools; Nursing Students Structured Questionnaire Sheet, OSCE Evaluation Questionnaire and Nursing students' feedback about OSCE questionnaire. Results: Finding of the present study revealed that most of the gerontological nursing students accepted the objective structured clinical examination as a tool for evaluating their clinical performance. They reported that OSCE was fair (77.9\%), covered a wide range of clinical skills and knowledge (76.5\% and $85.5 \%$ respectively), minimized the chance of failing and highlighted areas of weaknesses by more than two thirds of the students. Also, there was a significant correlation between the OSCE variables $(P=$ 0.000). Conclusion: Objective structured clinical examination seems to be an acceptable and beneficial method for evaluation of the gerontological nursing students' clinical skills. Moreover, objective structured clinical examination implementation in Mansoura University Faculty of Nursing provides an evidence about accepting this tool of evaluation as viewed by gerontological nursing students. Recommendations: Preparing standardized and approved OSCE stations for gerontological nursing course by a high committee from the faculty and the department in the future.
\end{abstract}

Keywords: Gerontological nursing; Objective structure clinical examination; Students' evaluation; Students' feedback.

\section{Introduction}

Nurses are the core for promoting positive patient outcomes, providing quality care, and reducing adverse events ${ }^{(1)}$. In addition, an aging population and technological developments have changed the way that health care is delivered ${ }^{(2)}$. In this complicated and ever-changing health care setting, theoretical and clinical skills are very essential for nurses to deliver effective and safe patient care ${ }^{(1)}$. This can be achieved through the assessment of undergraduate nursing students' competencies, which is considered as one of the ultimate complexes, varied, and challenging activities of the educational process facing nursing academics ${ }^{(3,4)}$.

Objective structured clinical examination (OSCE) is one form of objective evaluation method that is gaining more acceptances and is being adopted by educators of various disciplines ${ }^{(5)}$. OSCE was originally introduced in 1975 with the aim of assessing clinical competence in an objective, structured way among medical students $^{(6)}$. Now, OSCE is used in other branches of health sciences including dentistry, pharmacy and becomes a popular tool for assessing competency in clinical 
nursing ${ }^{(7,8)}$. OSCE is defined as "an approach to the assessment of clinical competence in which the components of competence are assessed in a well-planned or structured way with attention being paid to objectivity", ${ }^{(9)}$.

Objective structured clinical examination is carefully structured including parts from all elements of the curriculum as well as a wide range of skills to evaluate the achievement of educational goals in the areas of cognitive, emotional and psychomotor of nursing students ${ }^{(10,11)}$. Furthermore, OSCE is designed through creating a several short stations ranged from fifteen to twenty stations ${ }^{(12)}$. Students are assessed in different clinical competencies through moving from station to the next one while being watched by examiners and then scored using structured marking sheets ${ }^{(13)}$. Studies have shown that OSCEs with more stations of shorter duration have better reliability and validity of performance assessment than those with fewer and longer stations ${ }^{(14)}$.

The greater advantage of utilizing objective structured clinical examination is that, it may be established to merge theory and practice in kinds of case studies, small scenarios, simulations, standardized patient and the students can upgrade their own learning and reflection in very safe surroundings $^{(15,16)}$. The key strength of OSCE is in its standardization and reliability when compared to older forms of performance assessment. In order for the OSCE to get reliable results, it is essential to be careful to every and each element of quality assurance, as poorly standardized patients, untrained examiners, poor quality queries and inappropriate scoring rubrics each can have an effect on the reliability of the OSCE. The validity also will be affected if the questions are not realistic and mapped against the learning outcomes of the teaching program ${ }^{(17)}$. In the OSCE, evaluation of the clinical skills is crucial feedback and it plays a substantial motivating role between students and lecturers to confirm the standard and appropriateness of a learning process ${ }^{(18)}$.

The Department of Woman's Health and Midwifery Nursing introduced objective structured clinical examination for the first time in 2007 in Mansoura University Faculty of Nursing. OSCE had been utilized to evaluate the clinical performance of third year students after their completion of Maternity and Gynecology Course $^{(19)}$. Recently, OSCE has expanded in evaluating various clinical disciplines and there is no valid evidence to confirm or refuse the current structure and explore the students' views about the assessment tool especially in the field of gerontological nursing ${ }^{(20)}$. Despite a protracted tradition of research about OSCE, there have been relatively fewer studies in Mansoura University about the students' feedback of objective structured clinical examination as an assessment tool. Therefore, the evaluation of gerontological nursing students and feedback about the use of OSCE will enhance its future development, define some of deficiencies and obstacles in the preparation and conduction of the examination. Hence, students' evaluation and feedback about OSCE should be investigated.

\section{Aim of the Study}

Determine the gerontological nursing students' evaluation and feedback about objective structured clinical examination.

\section{$\underline{\text { Research Questions: }}$}

1. What is the gerontological nursing students' evaluation of objective structured clinical examination?

2. What is the gerontological nursing students' feedback about objective structured clinical examination as an evaluation tool? 


\section{Materials and Method}

\section{Materials}

Design: A descriptive exploratory research design was utilized to fit the nature of the study.

Setting: The study was carried out at the Faculty of Nursing, Mansoura University, Egypt.

Subjects: The study included all undergraduate $4^{\text {th }}$ level students enrolled in gerontological nursing course in the first and second semester during the academic year 2016/2017. The total number of the undergraduate students was 392 and only 289 of them agreed to participate in the study.

Tools:

Tool I: Nursing Students Structured Questionnaire Sheet

This tool was developed by the researchers to assess the study subjects' demographic characteristics and consists of items such as age, sex, residence and marital status.

\section{Tool II: OSCE Evaluation Questionnaire}

This tool was developed by Pierre et al. $(2004)^{(21)}$ and used for evaluation of OSCE. The questionnaire consists of 32 items. This tool was translated into Arabic and tested for its validity and reliability by Ali et al. $(2012)^{(22)}$. The reliability was assured by Spearman's correlation coefficient $r=0.77$. The Arabic version of the questionnaire was modified to give a clear meaning and become suitable to gerontological nursing assessment formats. For the aim of this study only 25 items were used. The questionnaire used in the current study consists of three main sections:

Section 1: This section is used to assess objective structured clinical examination attributes evaluation of nursing students, and it consists of 13 items as wide range of clinical skills and knowledge, fairness of the exam covered, time at each station, minimizes chance of failing, and objective structured clinical examination administration and organization. For each statement the student was asked to rate the responses on a 4-point Likert scale ranging: 'agree', 'neutral', 'disagree', and 'no comment'.

Section 2: This section is used to evaluate the nursing students' OSCE performance quality and it comprises 8 items including exam nature awareness of the students, exam tasks, exam structure and time adequacy for every station. The student was asked to rate the responses on a 3-point Likert scale ranging: 'to a great extent', 'neutral', and 'not at all'.

Section 3: This section is used to evaluate OSCE validity and reliability of nursing students and it consists of 4 items addressing the OSCE score standardization, and its objectivity and usefulness. The student was asked to rate the responses on a 3-point Likert scale ranging: 'to a great extent', 'neutral', and 'not at all'.

Tool III: Nursing Students' Feedback about OSCE Questionnaire

This tool was developed by the researchers and consists of 3 open questions. It was used to assess students' opinions about OSCE (Positive and negative aspects) and their suggestions for practical exam improvement. Responses were grouped according to thematic contents.

\section{Method}

- Approval to conduct the study was obtained from Dean of the Faculty of Nursing and the Head of gerontological nursing department to conduct the study.

- Study tools I (Nursing Students Structured Questionnaire Sheet) and III (Nursing Students' Feedback about OSCE Questionnaire) were developed by the researchers after reviewing the relevant literature. 
- The Arabic version of tool II (OSCE Evaluation Questionnaire) was used. Back-translation technique was used to assure the tool translation validity by English language expert from English Department, Faculty of Education, Mansoura University. The content validity of the questionnaires was obtained by five panels of experts in gerontological nursing and nursing education field (94\%) and the required corrections and modifications were done accordingly.

- Reliability of tool II (OSCE Evaluation Questionnaire) for the 25 items was asserted using spearman's correlation coefficient $\mathrm{r}=0.86$.

- A pilot study was carried out on 10 students before starting the data collection to ascertain the applicability and clarity of the study tools and the required modifications were done.

- The staff of Gerontological Nursing department prepared objective structured clinical examination stations. OSCE was prepared to cover the gerontological nursing course objectives. It involved 15 stations which included physiological and psychosocial changes of the older adults, clinical procedures, clinical management, health promotion activities, attitude toward elderly and elder abuse.

- Students were classified into 3 groups; examination of every group was done separately on a different day. The 3 objective structured clinical examinations were done in 3 consecutive days.

- Each station was based upon the course blueprint. Objective structured clinical examinations were done in 6 labs. Every lab had 15 station exam, 5 minutes duration for each station.

- The examination team involved all Gerontological Nursing staff members. Prior the actual exam, a training on OSCE was carried out for all the staff.
Prior the final OSCE a training package was prepared for training the students.

- The Gerontological Nursing objective structured clinical examination answer book was designed involving a cover sheet, a separate sheet for every station and a sheet for instructions. A standardized marking system was utilized in mark overall OSCE answer booklet. Before beginning the OSCE, one of the examiners point out the instruction to students.

- Instantly following the objective structured clinical examination, each student was told about the study nature, objective and significance of it. The students were encouraged to produce their feedback about objective structured clinical examination as a tool of assessment for their clinical skills. They were enlightened that their participation would not have an effect on them in any way. The questionnaire sheet was distributed to each student and picked up prior leaving the session.

\section{Ethical considerations:}

Ethical approval was taken from Mansoura University Faculty of Nursing Ethic Committee. Informed consent was obtained from the eligible students after explanation of nature of the study. The students were informed that their participation is voluntary and that they can withdraw from the study at any time. Anonymity and confidentiality of the data collected were assured.

\section{Statistical Analysis}

Statistical analysis was done by utilizing the Statistical Package for Social Science version sixteen. The data obtained were coded, analyzed and tabulated. Basic descriptive statistical analysis was carried out using; frequencies, means, standard deviations, and analytical statistics using; student t-test, and Spearman's correlation coefficient. The 0.05 and 0.01 levels were utilized as the cut off value for statistical significance. Qualitative analysis was 
performed using a form of content analysis; responses were grouped according to thematic contents.

\section{Results}

All Nursing students were enrolled in the gerontological nursing course, their age ranged from 21 to 24 years with a mean of $22.15 \pm .95$ years. Female constituted $79.6 \%$ of the studied students and the rest were males.

Table (1) shows the gerontological nursing students' evaluation of OSCE attributes, $77.9 \%$ of the studied students perceived OSCE as fair, $85.5 \%$ as covering a wide range of knowledge and $76.5 \%$ as covering a wide range of clinical skills. Moreover, well administered exam was reported by $81.0 \%$ of the studied students and well-structured and sequenced by $73.7 \%$. More than two thirds of the students $(68.2 \%)$ agree that, the exam minimizes the chance of failing, $69.5 \%$ help students to compensate in some areas to improve their grades, and $67.8 \%$ can identify the areas of weakness. View the exam as stressful and intimidating method were reported by $19.0 \%$ and $26.3 \%$ of the studied students respectively. While, $10.7 \%$ of the students reported that, the exam needs more time at stations.

Table (2) represents the gerontological nursing students' evaluation of the quality of OSCE performance. The results of the study revealed that, most of the students provided positive feedback about the quality of OSCE exam; $83.4 \%$ of them reported that, they were well oriented about the exam, and $77.9 \%$ the tasks were consistent with what they taught. Moreover, $78.2 \%$ and $78.5 \%$ of the students respectively felt that the tasks that they were asked to perform was fair and the time was adequate. $76.5 \%$ of them were satisfied with the given instructions and $81.7 \%$ with the sequence of stations. Also, $78.5 \%$ of students viewed that, the exam provides them with opportunities to learn.

Table (3) shows the gerontological nursing students' evaluation of OSCE validity and reliability. Results of the study revealed that, $92.7 \%$ of the studied students were not affected by gender or personality regarding the OSCE scores and 78.2\% reported that OSCE scores are standardized. The exam provides true measure of essential clinical skills and useful experience was reported by $79.6 \%$ and $83.7 \%$ of the students respectively.

Table (4) shows the gerontological nursing students distribution based on their performance level. More than half of the studied students $(55.4 \%)$ had excellent level of performance in the exam and $23.9 \%$ very good level of performance.

Table (5) shows the relation between gerontological nursing students' gender and the study variables. A statistically significant difference was found among gender of the gerontological nursing students. As, female had a positive view toward the exam rather than male. Also, female had higher score than male.

Table (6) (Qualitative data): Nursing students' feedback was examined with open ended questions. Responses were classified in consistent with the thematic contents. Among the positive aspects of the OSCE, students stated that the exam was fair to all students (98 comments), it had been less stressful than other exams (86 comments), and cover most of the curriculum and replicate what they learned (76 comments). However, there have been others negativities reported by some students because the time allotted to perform the tasks was insufficient (42 comments) and the exam was stressful (38 comments). The suggestions for improvement included; the time at every station should be increased (67 comments), and the students want more explanation about the exam (36 comments).

Table (7) represents the correlation between the study variables and the level of performance. A positive correlation between the OSCE attributes evaluation, the OSCE performance quality, validity and reliability of OSCE was found $(\mathrm{P}=0.000)$. As, the studied students have the same view towards OSCE evaluation. Also, a negative 
correlation between nursing students' level of performance and the study variables (OSCE attributes evaluation, OSCE performance quality, validity and reliability of OSCE) was found ( $\mathrm{P}=0.000)$. This means that, the level of performance was higher among students who had low point in the Likert scale (positive view towards the exam).

\section{Discussion}

Advanced nursing practice is concerned about decision-making based on a theoretical background, as in objective structured clinical examination (OSCE) which is considered an import issue in nursing education ${ }^{(18)}$. The OSCE has over the years emerged as a way of evaluating clinical skills in most medical and allied professions ${ }^{(23)}$. Moreover, students' feedback is considered a good indicator about the efficiency of the assessment tool and useful in improvements. The feedback received supports the applicability of this method in assessing the performance of nursing students ${ }^{(24)}$. Accordingly, this study was conducted to determine the nursing students' evaluation and feedback about objective structure clinical examination in the field of gerontological nursing.

The study findings pointed out that, most of gerontological nursing students accepted objective structured clinical examination as a tool for evaluation of their clinical performance in terms of fairness of the exam, covered a wide range of clinical skills and knowledge, well administered, structured, and sequenced. Also, ultimate number of gerontological nursing students viewed OSCE as an evaluation tool that minimizes the chance of failing, helps students to compensate in some areas to improve their grades, and can identify their areas of weakness (table 1). This positive view may be explained by the fact that OSCE was used in students' evaluation since several years and they are aware with the nature of the exam. These findings are confirmed by the quantitative marks of the students, as more than half of studied student had excellent level of performance in the gerontological nursing exam (table 4). These results are consistent with a study conducted in Egypt (2012) by Bayoumy and Yousri $^{(25)}$ who discovered that, all students were satisfied with OSCE as a strategy for assessment and in agreement on all organization and exams instructions positive aspects, overall perception of exam as well structured, fair, covering a wide area of skills and knowledge, well administered, allowed extra marks restitution and minimize failing chance. Other studies conducted in Egypt by El-Nemer and Kandeel (2009) ${ }^{(19)}$, Ali $(2012)^{(22)}$, Selim et al. $(2012)^{(26)}$, Al-Zeftawy and Khaton $(2016)^{(27)}$ and Saed and Abbas (2017) revealed the same findings. In addition, other studies conducted in USA by Beckham (2013) ${ }^{(29)}$, in Saudi Arabia by Hatamleh and Sabeeb $(2014)^{(5)}$, in Sudan by Abd Alla and Mohammed (2016) ${ }^{(30)}$, and in Kuwait by Omu (2016) ${ }^{(31)}$ are in accordance with the results of the present study and revealed that objective structured clinical examination was positively accepted and perceived as a new method to assess clinical skills by undergraduate nursing students.

The current study results revealed that, a high percentage of students recognized that OSCE was less stressful and intimidating experience (table 1). This perception might be justified by the students being totally aware earlier about the nature of the exam, from their experience in the previous three years in the faculty and also the examiners cooperation. This means that, the relaxed students can be easily tested than tensed one. The results of the present study come in congruent with studies performed in Egypt by Ahmed and Abu El Alla $(2014)^{(32)}$, Selim et al. (2012) ${ }^{(26)}$ and Al-Zeftawy and Khaton (2016) ${ }^{(27)}$ who found that, more than half of nursing students reported that, objective structured clinical examination was not stressful than other assessment tools. While, the findings of this study contradict the results of ElNemer and Kandeel (2009) ${ }^{(19)}$ who reported that, a substantial proportion of students reported that OSCE was intimidating and 
stressful experience, espicially 1 st year nursing students and attributed the contradiction to the fact that, Mansoura University Faculty of Nursing, performed the objective structured clinical examination for the first time. Also, Bayoumy and Yousri $(2012)^{(25)}$, Ali (2012) $)^{(22)}$, Selim et al. $(2012)^{(26)}$, and Abd Alla and Mohammed $(2016)^{(30)}$ contradict the findings of the current study.

In relation to objective structured clinical examination performance quality evaluation of students, this study results showed a positive feedback in terms of exam nature awareness, instructions clarity, stations sequences, and more learning opportunities provision (table 2). These are consistent with other previous studies which reported the same findings ${ }^{(19,22,25-27,30)}$. The current study added that, few percent of the studied students complained from insufficient time allowed for every station (table 2). Eswi et al. (2013) ${ }^{(33)}$ study conducted in Saudi Arabia supported these results, who said that, the time allowed for every station was adequate by the majority of the students. On the other hand, studies contradicting the present study results reported that, there are considerable high percentage of nursing students complained from insufficient time at OSCE stations $^{(25,26,30)}$.

Objective structured clinical examination was a valid and reliable method in nursing students' evaluation as evidenced by the feedback of gerontological nursing students in this study (table 3 ). Moreover, gerontological nursing students provides a positive feedback that objective structured clinical examination covers most of the curriculum and reflect what they learned, less stressful than other exams and fair to all students. Also, more than half of the studied students suggested increase the time of exam stations (table 6). The majority of the students view OSCE as a practical and useful experience, the scores were standardized and provided a real measure of essential clinical skills. Also, most of them reported that student's personality does not affect the scores of the exam (table 3). The objectivity of OSCE was highly supported by other research studies which showed that objective structured clinical examination was shown as a useful and positive practical experience ${ }^{(22,25,28,32,34)}$. The present research findings were further supported by asking the students to add comments about their feedback about the exam (table 6). While, Al-Zeftawy and Khaton $(2016)^{(27)}$ stated that, more than half of studied nursing students mentioned that, student's personality, ethnicity and gender mostly affect scores of OSCE. Possible explanation for this contradiction might justified by changes in the demographic characteristics of the studied students.

In the current study, although OSCE was seen as an acceptable evaluation tool by the majority of the gerontological nursing students, females showed more significant acceptance than males (table 5). This in agreement with Saeed et al. $(2016)^{(35)}$ study in Saudi Arabia who concluded that, females had more favorable rating of the OSCE compared to males. This confirmed by the fact in the study results that females had significant higher scores than males in the exam and it was consistent with Hadi et al. (2018) ${ }^{(36)}$ study in Saudi Arabia who reported that, female students had higher marks in the OSCE compared with male students. These findings may be justified by the fact that female students are keener to learn and concentrate on their studies than male students. While, other studies reported that gender was not significantly associated with the variables in the study ${ }^{(37,38)}$.

The results of this study showed significant positive correlation between all OSCE attributes (table 7). This indicates that all students have the same view towards all OSCE attributes. This correlation was supported by Eswi et al. $(2013)^{(33)}$ who represented correlation between the OSCE attributes as perceived by nursing students. Moreover, significant negative correlation was found between 
performance level of gerontological nursing students and the objective structured clinical examination attributes (table 7). It means that the level of performance was higher among students who viewed the exam positively (had low point in the Likert scale).

\section{Conclusion}

Objective structured clinical examination seems to be an acceptable and beneficial method for evaluation of the gerontological nursing students' clinical skills. Objective structured clinical examination implementation in Mansoura University Faculty of Nursing provides an evidence about accepting this tool of evaluation as viewed by gerontological nursing students in terms of fairness, unbiased, cover a wide range of clinical skills and knowledge, and standardized tool for assessment. Moreover, it appears that females were more satisfied with objective structured clinical examination than males.

\section{Recommendations}

- Improve OSCE by considering the suggestions that have been raised by the students in the future.

- Assuring clear revision and instructions about all training and competencies for objective structured clinical examination for undergraduate nursing students just before the examination.

- Preparing standardized and approved OSCE stations for gerontological nursing course by a high committee from the faculty and the department in the future.

\section{Acknowledgement}

We would like to thank all undergraduate nursing students and the faculty staff members in Gerontological Nursing Department - Mansoura University, who accepted to participate in this study and for their cooperation. 
Table (1): Gerontological nursing students' OSCE attributes evaluation ( $N=289)$

\begin{tabular}{|l|c|c|c|c|c||}
\hline Items & $\begin{array}{c}\text { Agree } \\
\mathbf{N}(\%)\end{array}$ & $\begin{array}{c}\text { Neutral } \\
\mathbf{N}(\%)\end{array}$ & $\begin{array}{c}\text { Disagree } \\
\mathbf{N}(\%)\end{array}$ & $\begin{array}{c}\text { No } \\
\text { comment } \\
\mathbf{N}(\%)\end{array}$ & Mean \pm SD \\
\hline Exam was fair & $225(77.9)$ & $42(14.5)$ & $15(5.2)$ & $7(2.4)$ & $1.42 \pm 0.82$ \\
\hline Wide knowledge area covered & $247(85.5)$ & $28(9.7)$ & $14(4.8)$ & $0(0.0)$ & $1.24 \pm 0.61$ \\
\hline Needed more time at stations & $31(10.7)$ & $33(11.4)$ & $218(75.4)$ & $7(2.4)$ & $2.05 \pm 0.56$ \\
\hline Exams well administered & $234(81.0)$ & $38(13.1)$ & $10(3.5)$ & $7(2.4)$ & $1.37 \pm 0.80$ \\
\hline Exams very stressful & $55(19.0)$ & $42(14.5)$ & $186(64.4)$ & $6(2.1)$ & $1.99 \pm 0.64$ \\
\hline $\begin{array}{l}\text { Exams well structured \& } \\
\text { sequenced }\end{array}$ & $213(73.7)$ & $46(15.9)$ & $24(8.3)$ & $6(2.1)$ & $1.46 \pm 0.83$ \\
\hline $\begin{array}{l}\text { Exam minimized chance of } \\
\text { failing }\end{array}$ & $197(68.2)$ & $43(14.9)$ & $40(13.8)$ & $9(3.1)$ & $1.52 \pm 0.85$ \\
\hline $\begin{array}{l}\text { OSCE less stressful than other } \\
\text { exams }\end{array}$ & $195(67.5)$ & $34(11.8)$ & $55(19.0)$ & $5(1.7)$ & $1.47 \pm 0.76$ \\
\hline $\begin{array}{l}\text { Allowed student to compensate } \\
\text { in some areas }\end{array}$ & $201(69.5)$ & $36(12.5)$ & $44(15.2)$ & $8(2.8)$ & $1.48 \pm 0.81$ \\
\hline Highlighted areas of weakness & $196(67.8)$ & $33(11.4)$ & $53(18.3)$ & $7(2.4)$ & $1.48 \pm 0.79$ \\
\hline Exam intimidating & $76(26.3)$ & $49(17.0)$ & $159(55.0)$ & $5(1.7)$ & $1.94 \pm 0.70$ \\
\hline $\begin{array}{l}\text { Student aware of level of } \\
\text { information needed }\end{array}$ & $204(70.6)$ & $44(15.2)$ & $36(12.5)$ & $5(1.7)$ & $1.48 \pm 0.81$ \\
\hline $\begin{array}{l}\text { Wide range of clinical skills } \\
\text { covered }\end{array}$ & $221(76.5)$ & $28(9.7)$ & $38(13.1)$ & $2(0.7)$ & $1.34 \pm 0.68$ \\
\hline Total mean score & \multicolumn{3}{|l|}{$1.56 \pm 0.36$} & & \\
\hline
\end{tabular}

Table (2): Gerontological nursing students' OSCE performance quality evaluation $(\mathrm{N}=\mathbf{2 8 9})$

\begin{tabular}{|l|c|c|c|c|}
\hline Items & $\begin{array}{c}\text { To great } \\
\text { extent } \\
\mathbf{N}(\%)\end{array}$ & $\begin{array}{c}\text { Neutral } \\
\mathbf{N}(\%)\end{array}$ & $\begin{array}{c}\text { Not at all } \\
\text { N (\%) }\end{array}$ & Mean \pm SD \\
\hline $\begin{array}{l}\text { Fully aware of nature of } \\
\text { exam }\end{array}$ & $241(83.4)$ & $32(11.1)$ & $16(5.5)$ & $1.22 \pm 0.53$ \\
\hline Tasks reflected those taught & $225(77.9)$ & $43(14.9)$ & $21(7.2)$ & $1.29 \pm 0.59$ \\
\hline $\begin{array}{l}\text { Time at each station was } \\
\text { adequate }\end{array}$ & $227(78.5)$ & $34(11.8)$ & $28(9.7)$ & $1.31 \pm 0.64$ \\
\hline $\begin{array}{l}\text { Setting and context at each } \\
\text { station felt authentic }\end{array}$ & $226(78.2)$ & $46(15.9)$ & $17(5.9)$ & $1.27 \pm 0.56$ \\
\hline $\begin{array}{l}\text { Instructions were clear and } \\
\text { unambiguous }\end{array}$ & $221(76.5)$ & $52(18.0)$ & $16(5.5)$ & $1.29 \pm 0.56$ \\
\hline $\begin{array}{l}\text { Tasks asked to perform } \\
\text { were fair }\end{array}$ & $226(78.2)$ & $44(15.2)$ & $19(6.6)$ & $1.28 \pm 0.57$ \\
\hline $\begin{array}{l}\text { Sequence of stations logical } \\
\text { and appropriate }\end{array}$ & $236(81.7)$ & $38(13.1)$ & $15(5.2)$ & $1.23 \pm 0.53$ \\
\hline $\begin{array}{l}\text { Exam provided } \\
\text { opportunities to learn }\end{array}$ & $227(78.5)$ & $38(13.2)$ & $24(8.3)$ & $1.29 \pm 0.61$ \\
\hline Total mean score & \multicolumn{3}{|l|}{$1.27 \pm 0.305$} & \\
\hline
\end{tabular}


Table (3): Gerontological nursing students' OSCE validity and reliability evaluation $(\mathrm{N}=\mathbf{2 8 9})$

\begin{tabular}{||l|c|c|c|c||}
\hline Items & $\begin{array}{c}\text { To great } \\
\text { extent } \\
\mathbf{N}(\%)\end{array}$ & $\begin{array}{c}\text { Neutral } \\
\mathbf{N}(\%)\end{array}$ & $\begin{array}{c}\text { Not at all } \\
\mathbf{N}(\boldsymbol{\%})\end{array}$ & Mean \pm SD \\
\hline $\begin{array}{l}\text { OSCE exam scores provide true } \\
\text { measure of essential clinical } \\
\text { skills }\end{array}$ & $230(79.6)$ & $34(11.8)$ & $25(8.6)$ & $1.29 \pm .61$ \\
\hline $\begin{array}{l}\text { OSCE scores are standardized } \\
\text { experience }\end{array}$ & $226(78.2)$ & $41(14.2)$ & $22(7.6)$ & $1.29 \pm .60$ \\
\hline $\begin{array}{l}\text { Personality, gender and } \\
\text { ethnicity will not affect OSCE } \\
\text { scores }\end{array}$ & $242(83.7)$ & $32(11.1)$ & $15(5.2)$ & $1.21 \pm .52$ \\
\hline Total mean score & $268(92.7)$ & $18(6.2)$ & $3(1.0)$ & $1.08 \pm .31$ \\
\hline
\end{tabular}

Table (4): Gerontological nursing students' level of performance

\begin{tabular}{|l|c|c|c||}
\hline \hline Level of performance & $\mathbf{N}=\mathbf{2 8 9}$ & $\mathbf{\%}$ & Mean \pm SD \\
\hline Poor & 3 & 1.0 & $28.91 \pm 1.04$ \\
\hline Fair & 11 & 3.8 & $33.88 \pm 3.09$ \\
\hline Good & 46 & 15.9 & $42.21 \pm 1.65$ \\
\hline Very good & 69 & 23.9 & $47.95 \pm 1.75$ \\
\hline Excellent & 160 & 55.4 & $56.34 \pm 2.92$ \\
\hline Total & 289 & 100.0 & $50.95 \pm 7.27$ \\
\hline
\end{tabular}

Table (5): Relation between gerontological nursing students' gender and the study variables

\begin{tabular}{|l|c|c|c||}
\hline Item & $\begin{array}{c}\text { Male } \\
\mathbf{N = 5 9}\end{array}$ & $\begin{array}{c}\text { Female } \\
\mathbf{N = 2 3 0}\end{array}$ & $\begin{array}{c}\text { Test of } \\
\text { significance } \\
\text { t-test (p) }\end{array}$ \\
\hline Evaluation of OSCE attributes & $1.67 \pm 0.51$ & $1.53 \pm 0.31$ & $2.6(0.008)^{*}$ \\
\hline $\begin{array}{l}\text { Assessment of the quality of OSCE } \\
\text { performance }\end{array}$ & $1.35 \pm 0.31$ & $1.25 \pm 0.29$ & $2.1(0.034)^{*}$ \\
\hline $\begin{array}{l}\text { Evaluation of OSCE validity and } \\
\text { reliability }\end{array}$ & $1.36 \pm 0.46$ & $1.18 \pm 0.29$ & $3.7(0.000)^{*}$ \\
\hline Level of performance & $45.9 \pm 7.5$ & $52.2 \pm 6.6$ & $6.3(0.000)^{*}$ \\
\hline
\end{tabular}

*Significant at $P \leq 0.05$ 
Table (6): Gerontological nursing students' feedback about OSCE

\begin{tabular}{|c|c|c|c|}
\hline Positive aspects & $\mathbf{N}^{\neq}=\mathbf{2 8 9}$ & Negative aspects & $\mathbf{N}^{\ddagger}=\mathbf{2 8 9}$ \\
\hline The examiners were fair with students & 15 & Not suitable for all students & 9 \\
\hline $\begin{array}{l}\text { Reduce chance of cheating due to lack of } \\
\text { time }\end{array}$ & 17 & $\begin{array}{l}\text { The exam needs high speed in } \\
\text { performance }\end{array}$ & 12 \\
\hline $\begin{array}{l}\text { Variety of questions enabled the students } \\
\text { to gain grades and decrease chance of } \\
\text { failing }\end{array}$ & 30 & Unclear instructions & 15 \\
\hline Highlights differences between students & 32 & $\begin{array}{l}\text { The questions need more } \\
\text { thinking and no time }\end{array}$ & 18 \\
\hline Exam measure the clinical skills & 35 & The exam was stressful & 38 \\
\hline Save time and efforts & 38 & $\begin{array}{l}\text { Time allocated to perform } \\
\text { tasks were insufficient }\end{array}$ & 42 \\
\hline $\begin{array}{l}\text { The students have feedback about OSCE } \\
\text { before the time of the exam }\end{array}$ & 44 & & \\
\hline Not exhausting & 45 & & \\
\hline Easy, clear and simple & 49 & & \\
\hline The exam was organized & 61 & & \\
\hline $\begin{array}{l}\text { Cover most of the curriculum and reflect } \\
\text { what they learned }\end{array}$ & 76 & & \\
\hline Less stressful than other exams & 86 & & \\
\hline Fair to all students & 98 & & \\
\hline \multicolumn{4}{|l|}{ Suggestions: } \\
\hline \multicolumn{3}{|c|}{ The students need to take a period of rest between stations } & 7 \\
\hline \multicolumn{3}{|c|}{ Cooperation of the examiners can decrease the level of stress } & 9 \\
\hline \multicolumn{3}{|c|}{ Increase number of stations to decrease the grade of each station } & 16 \\
\hline \multicolumn{3}{|c|}{ The students need the exam's time as a total not divided into stations } & 18 \\
\hline \multicolumn{3}{|c|}{ The students need to practice sessions before the exam as training } & 24 \\
\hline \multicolumn{3}{|c|}{ The students need more explanation from the examiners about the exam } & 36 \\
\hline \multicolumn{3}{|c|}{ The time at each station should be increased } & 67 \\
\hline
\end{tabular}

$\neq$ Multiple responses

Table (7): Correlation between the study variables

\begin{tabular}{|c|c|c|c|c|c|c|c|c|}
\hline \multirow[t]{2}{*}{ Item } & \multicolumn{2}{|c|}{$\begin{array}{c}\text { OSCE attributes } \\
\text { evaluation }\end{array}$} & \multicolumn{2}{|c|}{$\begin{array}{c}\text { OSCE } \\
\text { performance } \\
\text { quality } \\
\text { evaluation } \\
\end{array}$} & \multicolumn{2}{|c|}{$\begin{array}{l}\text { OSCE validity } \\
\text { and reliability } \\
\text { evaluation }\end{array}$} & \multicolumn{2}{|c|}{$\begin{array}{c}\text { Students } \\
\text { performance } \\
\text { level }\end{array}$} \\
\hline & $\mathbf{r}$ & $\mathbf{P}$ & $\mathbf{r}$ & p & $\mathbf{r}$ & $\mathbf{p}$ & $\mathbf{r}$ & $\mathbf{p}$ \\
\hline $\begin{array}{l}\text { OSCE attributes } \\
\text { evaluation }\end{array}$ & - & - & 0.328 & $\begin{array}{c}0.000 * \\
*\end{array}$ & 0.220 & $\begin{array}{c}0.000 * \\
*\end{array}$ & -0.219 & $\begin{array}{c}0.000^{*} \\
*\end{array}$ \\
\hline $\begin{array}{l}\text { OSCE performance } \\
\text { quality evaluation }\end{array}$ & - & - & - & - & 0.409 & $\begin{array}{c}0.000 * \\
*\end{array}$ & -0.358 & $\begin{array}{c}0.000^{*} \\
*\end{array}$ \\
\hline $\begin{array}{l}\text { OSCE validity and } \\
\text { reliability evaluation }\end{array}$ & - & - & - & - & - & - & -0.383 & $\begin{array}{c}0.000 * \\
*\end{array}$ \\
\hline $\begin{array}{l}\text { Students performance } \\
\text { level }\end{array}$ & & & & & & & & \\
\hline
\end{tabular}

**Significant correlation at 0.01 


\section{References}

1. Butler M, Collins R, Drennan J, Halligan P, O'Mathuna D, Schultz T, Vilis E. Hospital nurse staffing models and patient and staffrelated outcomes. Cochrane Database Systematic Review. 2011. Available at: http://dx.doi.org.

2. Grady P. Advancing the health of our aging population: A lead role of nursing science. Nursing Outlook 2011; 59 (4): 207-9.

3. Abdelaziz A, Hany M, Atwa H, Talaat W, Hosny S. Development, implementation, and evaluation of an integrated multidisciplinary objective structured clinical examination (OSCE) in primary health care settings within limited resources. Medical Teacher 2015; 38 (3): 272-9.

4. Ryan K, Godson N. Nursing \& Health Survival Guide: Objective structured clinical examination. $2^{\text {nd }}$ ed., USA: Routledge, 2014: 3.

5. Hatamleh W, Abu Sabeeb Z. Perception of nursing faculty members on the use of objective structured clinical examinations (OSCE) to evaluate competencies. Journal of Nursing and Health Science 2014; 3(6): 21-6.

6. Harden R. What is an OSCE? Medical Teacher 1988; 10 (1): 19-22.

7. Al Nazzawi A. Dental students' perception of the objective structured clinical examination (OSCE): The Taibah University experience, Almadinah Almunawwarah, KSA. Journal of Taibah University Medical Sciences 2017; 13 (1): 64- 9 .

8. Awad L, Alshamandy S, Abolwafa N. Perception of undergraduate nursing students towards objective structured clinical examination (OSCE). Journal of Nursing and Health Science 2017; 6 (5): 52-60.

9. Harden R, Stevenson M, Downie W and Wilson G. Assessment of clinical competence using objective structured examination. British Medical Journal 1975; 1(5955): 44751.

10. Pishkar Mofrad Z, Navidian A, Robabi H. An assessment of traditional and objective structured practical evaluation methods on satisfaction of nursing students in Zahedan Faculty of Nursing and Midwifery: A comparing. Journal of Medical Education and Development 2013; 7(4): 2-14.

11. Abdel-Gawad N, Kassem I. Assessment of students' knowledge, clinical performance and satisfaction with objective structured clinical exam. Medical Journal Cairo University 2009; 77(4): 287-93.

12. Harden R. Twelve tips for organizing an objective structured clinical examination (OSCE). Medical Teacher 1990; 12 (34):259-64.

13. Zayyan M. Objective structured clinical examination: The assessment of choice. Oman Medical Journal 2011; 26(4): 219-22.

14. Strano-Paul L. OSCE geriatric patient with fall and cognitive impairment: Margaret Donovan. Portal of Geriatrics Online Education. 2011. Available at: https://pogoe.org.

15. Al Saif A, Alsenany S. The objective structured clinical exam (OSCE): A qualitative study exploring physical therapy student's experience. Journal of American science 2013; 9(6):615-21.

16. Frantz J, Rowe M, Hess D, Rhoda A, Sauls B, Wegner L. Student and staff perceptions and experiences of the introduction of objective structured practical examinations: A pilot study. African Journal of Health Professions Education 2013; 5 (2): 72-4.

17. Kamran Z, Kathryn G, Sankaranarayanan R and Piyush P. The objective structured clinical examination (OSCE): AMEE Guide No. 81. Part II: Organisation \& Administration, Medical Teacher 2013; 35:9.

18. Alsenany S, Al Saif A. Developing skills in managing objective structured clinical examinations (OSCE). Life Science Journal 2012; 9(3):597-602.

19. El-Nemer A, Kandeel N. Using OSCE as an assessment tool for clinical skills: Nursing students' feedback. Australian Journal of Basic and Applied Sciences 2009; 77(4): 45764. 
20. Negahdary R, Falsafy P, Bohluli S, Fakhrzadeh V, Eslami H, Purnasrollah A. Evaluation of the post-graduated students' perception about objective structured clinical examinations (OSCE) in Dentistry Faculty of Tabriz University of Medical Sciences in 2013-14. Biomedical \& Pharmacology Journal 2016; 9 (1): 67-72.

21. Pierre R, Wierenga A, Barton M, Michael B, Christie C. Student evaluation of an OSCE in pediatric at the University of the West Indies, Jamaica. BMC Medical Education 2004; 4 (22): 1-7.

22. Ali G, Mehdi A, Ali H. Objective structured clinical examination (OSCE) as an assessment tool for clinical skills in Sohag University: Nursing students' perspective. Journal of Environmental Studies 2012; 8: 59-69.

23. Jones A, Pegram A, Fordham-Clarke C. Developing and examining an objective structured clinical examination. Nurse Education Today 2010; 30 (2): 137-41.

24. Killingley J, Dyson S. Student midwives' perspectives on efficacy of feedback after objective structured clinical examination. British Journal of Midwifery 2016; 24(5): 362-71.

25. Bayoumy H, Yousri H. Objective structured clinical examination (OSCE) - based assessment in nursing: Students' and clinical instructors' perception. Journal of American Science 2012; 8 (9): 523-40.

26. Selim A, Ramadan F, El-Gueneidy M, Gaafer M. Using objective structured clinical examination (OSCE) in undergraduate psychiatric nursing education: Is it reliable and valid? Nurse Education Today 2012; 32(3): 283-8.

27. Al-Zeftawy A, Khaton S. Student evaluation of an OSCE in community health nursing clinical course at Faculty of Nursing, Tanta University. IOSR Journal of Nursing and Health Science 2016; 5 (4): 68-76.

28. Saed A, Abbas N. Feedback of undergraduate nursing students about objective structured practical examination. Journal of Nursing Education and Practice 2017; 7(3): 68-76.
29. Beckham N. Objective structured clinical evaluation effectiveness in clinical evaluation for family nurse practitioner students. Clinical Simulation in Nursing 2013; 9 (10): 453-9.

30. Abd Alla A, Mohammed K. The objective structured clinical exam (OSCE): A qualitative study evaluating nursing student's experience. International Journal of Science and Research 2016; 5 (3): 399-402.

31. Omu F. Attitudes of nursing faculty members and graduates towards the objective structured clinical examination (OSCE). Open Journal of Nursing 2016; 6 (5): 353-64.

32. Ahmed I, Abu El Alla L. Assessment of objective structured clinical examination (OSCE) regarding clinical competence and stressors: Nursing students' perspectives. Alexandria Scientific Nursing Journal 2014; 16(1): 75-92.

33. Eswi A, Badawy A, Shaliabe H. OSCE in maternity and community health nursing: Saudi nursing student's perspective. American Journal of Research Communication 2013; 1(3): 143- 62.

34. Mater E, Ahmad E, El Sayed A, Elsheikh M, Farag M. The impact of the objective structured clinical examination approach for clinical evaluation skills on the student's performance in nursing college. World Journal of Medical Sciences 2014; 11(4): 609-13.

35. Saeed A, Al Suwayh W, Alomri A. Students' perceptions and attitudes towards objective structured clinical examination (OSCE) in the College of Medicine, KSAU-HS, King Fahad Medical City, Riyadh, Saudi Arabia. Journal of Medical Science and Clinical Research 2016; 4 (3): 9741-7.

36. Hadi M, Ali M, Haseeb A, Mohamed M, Eleggal M, Cheema E. Impact of test anxiety on pharmacy students' performance in Objective Structured Clinical Examination: A cross-sectional survey. International Journal of Pharmacy Practice 2018; 26 (2): 191-4. 
37. Brand H, Schoonheim-Klein M. Is the OSCE more stressful? Examination anxiety and its consequences in different assessment methods in dental education. European Journal of Dental Education 2009; 13(3): 147-53.
38. Colbert C, McNeal T, Lezama M, Chandler M, Forrester L, Metting A, Mirkes C, Van Cleave H, Win S, David M. Factors associated with performance in an internal medicine clerkship. The peer-reviewed journal of Baylor Scott \& White Health 2017; 30 (1): 38-40. 